\title{
Prenatal dexamethasone exposure exerts sex-specific effect on placental oxygen and nutrient transport ascribed to the differential expression of IGF2
}

\author{
Juanjuan Guo ${ }^{1,2}$, Man Fang ${ }^{3}$, Siying Zhuang ${ }^{1}$, Yuan Qiao ${ }^{1,2}$, Wen Huang ${ }^{1}$, Qing Gong ${ }^{1}$, Dan Xu ${ }^{1,2}$, \\ Yuanzhen Zhang $^{1,2}$, Hui Wang ${ }^{1,2,3}$
}

${ }^{1}$ Department of Obstetrics and Gynecology, Zhongnan Hospital of Wuhan University, Wuhan 430071, China; ${ }^{2}$ Hubei Provincial Key Laboratory of Developmentally Originated Diseases, Wuhan 430071, China; ${ }^{3}$ Department of Pharmacology, Basic Medical School of Wuhan University, Wuhan 430071, China

Contributions: (I) Conception and design: J Guo, Y Zhang, H Wang; (II) Administrative support: H Wang; (III) Provision of study materials or patients: J Guo, D Xu, M Fang, S Zhuang, Y Qiao, W Huang, Y Zhang, H Wang; (IV) Collection and assembly of data: J Guo, D Xu, M Fang, S Zhuang, Y Qiao, W Huang; (V) Data analysis and interpretation: J Guo, Q Gong; (VI) Manuscript writing: All authors; (VII) Final approval of manuscript: All authors.

Correspondence to: Hui Wang; Yuanzhen Zhang. Department of Obstetrics and Gynecology, Zhongnan Hospital of Wuhan University, 169 Donghu Road, Wuchang District, Wuhan 430071, China. Email: wanghui19@whu.edu.cn; zhangyuanzhen@vip.sina.com.

Background: Clinical studies have showed that dexamethasone exposure during pregnancy could cause fetal growth retardation, but the mechanism by which prenatal dexamethasone exposure influences placental nutrient transport is still unclear. This study investigated the impacts of prenatal dexamethasone on the placental oxygen and nutrient transport.

Methods: Pregnant Wistar rats were subcutaneously administered with dexamethasone from day 9 to day 20 of gestation at 0.2 or $0.8 \mathrm{mg} / \mathrm{kg} \cdot \mathrm{d}$. Pregnant rats were sacrificed on gestational day 20. The placental tissue was collected for analysis.

Results: Prenatal dexamethasone exposure (PDE) declined the fetal weight and increased the intrauterine growth retardation (IUGR) rate in a dose-dependent manner. The total placental volume and the length, density and surface area of fetal capillaries in the labyrinth zone reduced in a dose-dependent manner. In addition, the thickness of syncytial membrane dose-dependently increased, resulting in a dose-dependent decrease in oxygen diffusion capacity. Furthermore, after PDE, the nutrient transport area and oxygen diffusion capacity of male placenta were lower than that of female placenta. The mRNA and protein expression of placental nutrient transporters including glucose transporter 1 (GLUT1), glucose transporter 3 (GLUT3), L-type amino acid transporter 1 (LAT1), lipoprotein lipase (LPL) and scavenger receptor class B type 1 (SRB1) increased in female placenta. However, in male placenta, the expression of LAT1, LPL and SRB1 was significantly decreased and GLUT1 and GLUT3 have a decrease trend. We further investigated the expression of insulin-like growth factor 1 (IGF1) and insulin-like growth factor 2 (IGF2) related to placental and fetal growth and development. Our study showed that the expression of IGF1 was significantly decreased both in male and female placentas after PDE. But the expression of IGF2 was significantly increased in female placentas while significantly decreased in male placentas.

Conclusions: Our study shows prenatal dexamethasone exposure exerts sex-specific influence on the placental oxygen and nutrient transport. This might be ascribed to the differential expression of IGF2 after PDE. These findings provide evidence on the dexamethasone-induced toxicity to the placenta and fetal development. 
Keywords: Prenatal dexamethasone exposure (PDE); intrauterine growth retardation (IUGR); nutrient transport; placenta; sex difference

Submitted Sep 01, 2019. Accepted for publication Dec 11, 2019.

doi: $10.21037 /$ atm.2019.12.156

View this article at: http://dx.doi.org/10.21037/atm.2019.12.156

\section{Introduction}

Glucocorticoids, especially dexamethasone, can pass through the placenta and play an irreplaceable role in promoting fetal lung maturation (1). In many countries, glucocorticoid is a standard treatment to preterm birth in pregnant women at a gestational age of $<34$ weeks $(2,3)$. As the risk of preterm birth is nearly $10 \%$ in pregnant women, a large proportion of pregnant women receive glucocorticoid therapy (4). However, both animal and clinical studies have revealed that prenatal dexamethasone exposure (PDE) can cause intrauterine growth retardation (IUGR) (5). IUGR is defined as fetal weight less than the 10th percentile for the gestational age or two standard deviations below the normal (6). IUGR is associated with fetal distress, stillbirth, neonatal asphyxia, death, and other complications $(7,8)$. In addition, IUGR fetuses have a higher risk of developing metabolic syndrome in childhood and adulthood (9). In our previous study, results showed PDE induced toxicity to the fetal developmental, and the underlying mechanism may be ascribed to that dexamethasone may depress the fetal adrenal function (10). Miller et al. found that fetuses with IUGR due to glucocorticoids exposure were more susceptible to growth-restriction than IUGR fetuses without glucocorticoids exposure and appropriately grown fetuses with glucocorticoids exposure (11). In addition, it has been shown that male and female fetuses respond differently to the factors related to growth restriction, including the sexrelated difference in the placental endocrine function (12).

Intrauterine fetal development depends on the capacity of placental oxygen and nutrient transportation from maternal circulation (13). Decreased placental oxygen and nutrient transport may lead to IUGR (14). The placenta is essential for the survival and growth of the fetus because it forms the interface between the maternal and fetal circulatory systems, promotes metabolism and gas exchange, and clears fetal waste (15). In mice, fetal capillaries and maternal sinusoids are separated by a trilaminar layer of trophoblast cells: a bilayer of syncytiotrophoblasts surrounds the fetal vascular endothelium, and a layer of monocytes is arranged on maternal blood sinuses (16). Therefore, the nutrients and gases must across four layers to diffuse or be transported from one blood compartment to another. The overall surface area, diffusion distance and specific nutrient transporters influence the overall diffusion capacity of the placenta (17).

However, little is known about the effects of PDE on the placental oxygen and nutrient transport. The present study aimed to explore the effects of PDE on placental oxygen and nutrient transport. Stereology is a well-established method to generate the absolute three-dimensional quantities from two-dimensional histological sections, such as volume, surface area, and length of complex tissues (18). This study will provide a theoretical and experimental basis for further understanding of the dexamethasone-induced toxicity to the placenta and fetal development as well as of the intrauterine origin of diseases in adults.

\section{Methods}

\section{Drugs and reagents}

Dexamethasone (in ampoules) was purchased from Shuanghe Pharmaceutical Company (Wuhan, China). Trizol reagent and DNA extraction kit were obtained from Omega Bio-Tek (Doraville, USA). Real-time quantitative PCR (RT-qPCR) kits were purchased from Takara Biotechnology Co., Ltd. (Dalian, China) and Sangon Biotech Co., Ltd. (Shanghai, China) synthesized the primers. Other reagents were analytical reagents. The primer sequences are shown in Table 1.

\section{Animals and treatment}

Specific pathogen-free (SPF) Wistar rats (females: 200-240 g; males: 260-300 g) were obtained from the Experimental Center of Medical Scientific Academy of Hubei (China, No. 2008-0005). Animal experiments were conducted in the Center for Animal Experiment of Wuhan University (Wuhan, Hubei, China), which is accredited by the Association for Assessment and Accreditation of Laboratory Animal Care International (AAALAC 
Table 1 Primers used for real-time quantitative PCR

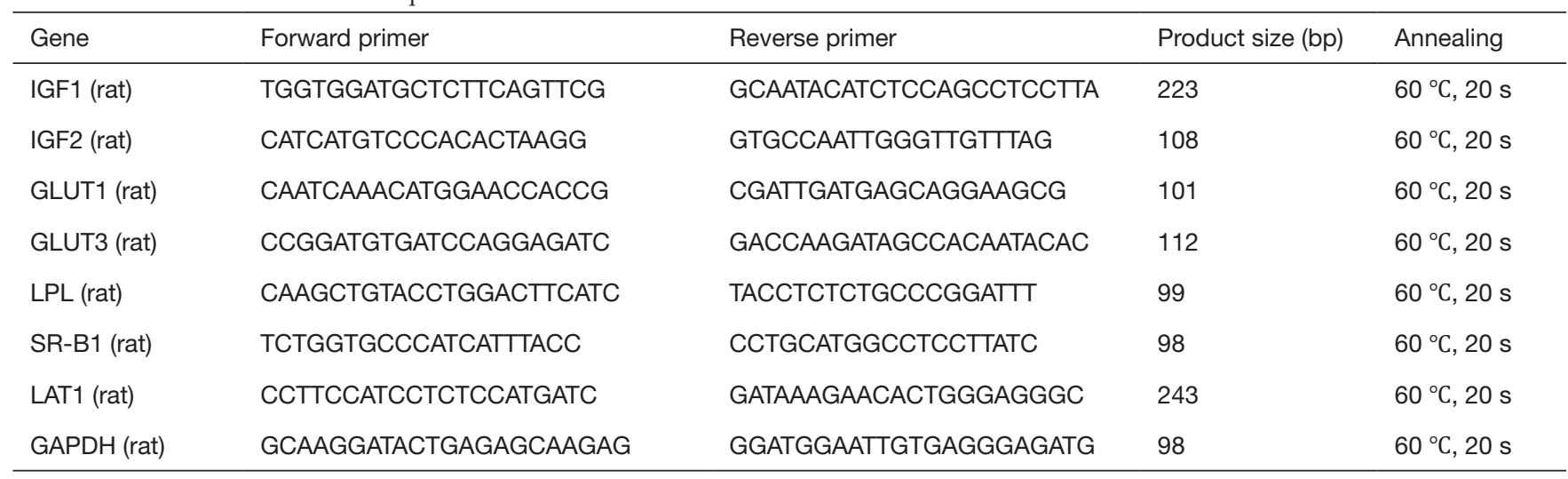

IGF1, insulin-like growth factors-I; IGF2, insulin-like growth factors II; GLUT1, glucose transporter 1; GLUT3, glucose transporter 3; LPL, lipoprotein lipase; SR-B1, scavenger receptor class B type 1; LAT1, L-type amino acid transporter 1; GAPDH, glyceraldehyde phosphate dehydrogenase.

International). All the experimental procedures were carried out according to the guidelines for the Care and Use of Laboratory Animals of the Chinese Animal Welfare Committee. The details for raising and mating Wistar rats had been mentioned earlier (19). The sperm-positive vaginal smear was used to assess the successful mating, and the day of successful mating was defined as gestational day (GD) 0. Subsequently, pregnant rats were randomly assigned to the control group and the dexamethasone group. The pregnant rats in dexamethasone group were injected subcutaneously with dexamethasone at $0.2 \mathrm{mg} / \mathrm{kg} \cdot \mathrm{d}$ (low dose) or $0.8 \mathrm{mg} / \mathrm{kg} \cdot \mathrm{d}$ (high dose) from GD9 to GD20; in the control group, rats were injected subcutaneously with the same volume of saline. In the experiment for fetal rats, 11 pregnant rats in each group were anesthetized with $2-3 \%$ isoflurane on GD20. The fetuses were quickly collected, and the bodyweight, diameter, and volume were measured with the drainage method. Fetal placentas were also collected for further analysis.

\section{Tissue collection and preparation}

All the placentas were divided into two parts along the largest diameter. One was fixed overnight in $10 \%$ formaldehyde, embedded in paraffin and then sectioned $(5 \mu \mathrm{m})$, followed by hematoxylin and eosin (HE) for routine histological examination. Immunohistochemistry for CD31 was done to assess the fetal capillaries. The remaining placental tissues were immediately placed into liquid nitrogen and subsequently stored at $-80{ }^{\circ} \mathrm{C}$ for further analysis.

\section{Tissue analysis}

The placental volume, surface area, mean capillary length and diameter and diffusing capacity of the interhemal membrane were determined with the square gad test system via the Image-Pro analysis software. Each testing point was 30 pixels distant. Before testing, the gad should be scaled.

\section{Stereology}

\section{Absolute placental volume}

The placentas were fixed in Bouin's fluid for $24 \mathrm{~h}$. The volume of placenta was measured by weighing displaced fluid (20).

At a magnification of $20 \times, 12$ fields on the sections were measured by point counting to estimate the volume of the labyrinth zone (Lz) using the following equation:

$$
\mathrm{V}(\mathrm{Lz})=\mathrm{P}_{(\mathrm{Lz})} / \mathrm{P}_{(\text {total })}
$$

$\mathrm{V}(\mathrm{Lz})$ : the volume of labyrinth zone. $\mathrm{P}_{(\mathrm{Lz} z)}$ : the number of points falling on the labyrinth zone. $\mathrm{P}$ (total): the total number of points falling on the placenta

\section{Capillary length densities}

Fetal vascular endothelial cells of placenta were labeled with CD31 monoclonal antibody. A counting frame with two contiguous forbidden lines was used to obtain the capillary length density. The number of capillary distribution observed was recorded and the numerical density of 
capillary distribution per unit area of labyrinth QA was determined. Therefore, fetal capillary length density could be calculated as follows:

$$
\operatorname{Lv}(\text { cap })=2 \mathrm{QA}
$$

\section{Surface densities and surface area}

In each field of view, the surface densities of fetal capillaries were obtained by using the mesh formed by cycloidal arc, and the intercepts between the boundary of fetal capillaries were calculated. The following equation was used to determine the surface area:

$$
\mathrm{S}(\mathrm{fc})=\left(2 \times \sum \mathrm{I}_{(\mathrm{fc})} / \mathrm{I}_{(\mathrm{p})} \times \sum \mathrm{P}_{(\text {ref })}\right) \times \mathrm{V}_{\text {(placenta) }}
$$

$\mathrm{S}(\mathrm{fc})$ : fetal capillary surface area. $\Sigma \mathrm{I}(\mathrm{fc})$ : the total number of intersections of the cycloid arcs with the fetal capillary. $\Sigma \mathrm{P}(\mathrm{ref})$ : the total number of points that hit the reference space. $I_{(p)}$ : the length of the test line associated with each point in the grid (21).

\section{Interhemal membrane thickness}

The interhemal membrane thickness $\left(l_{h}\right)$ of the $\mathrm{Lz}$ was obtained with interception measurement method (22). Harmonic mean thickness $\left(\overline{t_{\mathrm{h}}}\right)$ was calculated as follows:

$$
\begin{aligned}
& \bar{l}_{\mathrm{h}}=2 / 3 \times \bar{l}_{\mathrm{h}} \\
& \overline{l_{\mathrm{h}}}: \text { harmonic mean of the intercept. }
\end{aligned}
$$

\section{Diffusion capacity for the interhemal membrane}

The theoretical diffusion capacity $\left(\mathrm{DC}_{\mathrm{t}}\right)$ was calculated as follows:

$$
\mathrm{DC}_{\mathrm{t}}=\mathrm{K} \times\left(\text { Surface area } / \overline{\mathrm{t}}_{\mathrm{h}}\right)
$$

$\mathrm{DC}_{\mathrm{t}}$ : the diffusing capacity across the interhemal membrane. K: Krogh diffusion coefficient for oxygen. Surface area: fetal capillary surface area. $\overline{t_{\mathrm{h}}}$ : the harmonic mean thickness of the interhemal membrane.

The specific diffusion capacity $\left(\mathrm{DC}_{\mathrm{s}}\right)$ was obtained as following equation:

$$
\mathrm{DC}_{\mathrm{s}}=\mathrm{DC}_{\mathrm{t}} / \text { fetal weight }
$$

\section{Isolation of total RNA and real-time quantitative RT-PCR}

Total RNA was isolated from placentas as previously described (23). Trizol reagent was used to extract total RNA from the placental tissues. The mRNA expression of IGF1/2, GIUT1, GLUT3, SNAT1, LPL, and SRB1 was detected by RT-qPCR. The primers used for RT-qPCR were designed with Premier 6.0. The Primer sequences are shown in Table 1. RT-qPCR was conducted with the ABI Step One Plus ${ }^{\mathrm{TM}}$ real-time PCR System (Applied Biosystems, Foster City, CA, USA) in $10 \mu \mathrm{L}$ of a mixture containing $1 \mu \mathrm{L}$ of cDNA template, $0.2 \mu \mathrm{L}$ of each primer, $5 \mu \mathrm{L}$ of SYBR Green and $3.6 \mu \mathrm{L}$ of DEPC- $\mathrm{H}_{2} \mathrm{O}$. The PCR conditions were as follows: pre-denaturation at $95^{\circ} \mathrm{C}$ for $30 \mathrm{~s}$ and then 40 cycles of denaturation at $95{ }^{\circ} \mathrm{C}$ for $5 \mathrm{~s}$; annealing conditions for each gene are shown in Table 1. GAPDH mRNA expression was detected simultaneously and used to normalize the expression of IGF1/2, GIUT, GLUT3, LAT1, LPL, and SRB1. Relative expression of each gene was calculated by the method of cycle threshold (CT) in the formula of $2^{-\Delta \Delta C t}$.

\section{Total protein extract and Western Blotting assay}

Fifty $\mathrm{mg}$ tissue was minced and rinsed 3 times with precooled PBS at $4{ }^{\circ} \mathrm{C}$, then lysed for $30 \mathrm{~min}$ in RIPA lysis buffer containing Protease Inhibitor Cocktail. The concentration of total protein was then determined with the BCA Assay kit. The total protein concentration of each group was adjusted to be consistent. Thirty $\mathrm{mg}$ of total protein was loaded into each lane. Proteins of different molecular weight were separated by electrophoresis in $10 \%$ sodium dodecyl sulfate polyacrylamide gel electrophoresis (SDS-PAGE) gel and then absorbed into PVDF membranes (Millipore, MA, USA). Then membranes were blocked in $5 \%$ fat-free milk for 1 hour at room temperature. After blocking, the membranes were incubated with primary antibody including GLUT1, GLUT3, SR-B1, LPL, LAT1 and GAPDH overnight at $4{ }^{\circ} \mathrm{C}$. They were then incubated with horseradish peroxidase (HRP)-conjugated secondary antibody at room temperature for $1 \mathrm{~h}$ and visualized with ECL HRP substrate (PerkinElmer Inc. Boston, Mass). Antibody binding signals were detected by the Chemi-doc Image Analyzer (Bio-Rad, Hercules, California). Relative protein level was standardized by GAPDH protein level. Image $\mathrm{J}$ was used to analyze the protein band intensities from three separate bands.

\section{Statistical analysis}

SPSS version 20.0 was used for statistical analysis. All the data are expressed as mean \pm standard error (S.E.M). Data were compared with $t$-test between two groups and with one-way analysis of variance (ANOVA) among groups. Chi-square analysis was performed to test for a difference in proportions of categorical variables between 
A

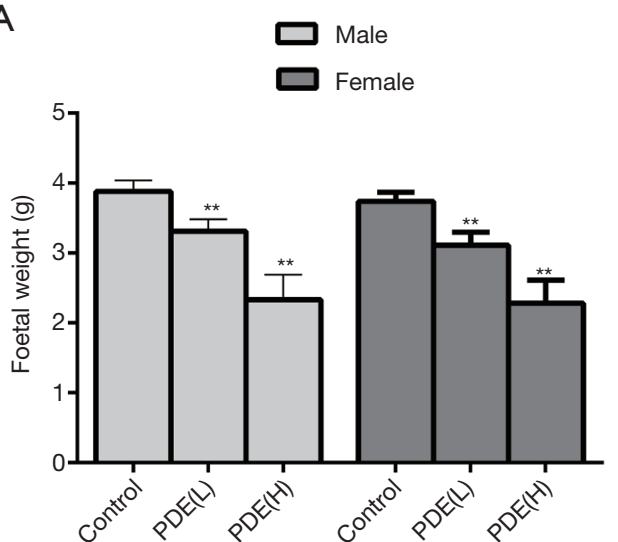

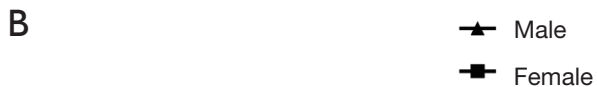

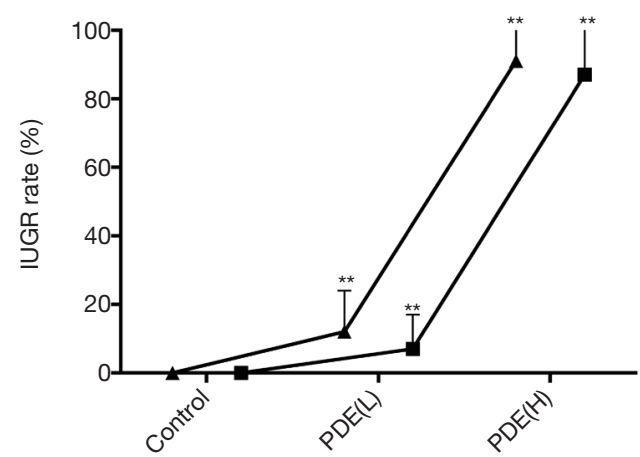

Figure 1 Effects of prenatal dexamethasone exposure (PDE) on the fetal weight (A) and IUGR rate (B). Data are presented as the mean \pm S.E.M., $\mathrm{n}=11$ in each group. ${ }^{* *}, \mathrm{P}<0.01$ vs. corresponding controls. PDE (L): $0.2 \mathrm{mg} / \mathrm{kg} \cdot \mathrm{d} ; \mathrm{PDE}$ (H): $0.8 \mathrm{mg} / \mathrm{kg} \cdot \mathrm{d}$.

groups. A value of $\mathrm{P}<0.05$ was considered statistically significant.

\section{Results}

\section{Effects of PDE on the rat fetal weight and IUGR rate}

Pregnant rats were subcutaneously treated with dexamethasone from GD9 to GD20, and sacrificed at GD20. Figure 1 shows a significant dose-dependent relationship between dexamethasone exposure and fetal weight, as dexamethasone exposure reduces fetal weight and increases IUGR rates $(\mathrm{P}<0.01)$. To be specific, the IUGR rate was augmented to $12.0 \%$ and $91.0 \%$ in 0.2 and $0.8 \mathrm{mg} / \mathrm{kg}$ dexamethasone male groups, respectively, while, the IUGR rate was augmented to $7.0 \%$ and $87.0 \%$ in 0.2 and $0.8 \mathrm{mg} / \mathrm{kg}$ dexamethasone female groups, respectively.

\section{Decreased placental weight and volume after PDE}

The placental weight is closely related to poor fetal prognosis (24), and the placental volume is an independent predictor of fetal growth retardation (25). In this study, the results showed PDE declined the placental volume (Figure $2 A, B, \mathrm{P}<0.01$ ) and weight (Figure $2 C, \mathrm{P}<0.05)$ in dosedependent manners. However, the ratio of birthweight to placental weight remained unchanged (Figure 2D).

\section{Changes in the nutrient transport surface area at the placental labyrinth zone after PDE}

The placental labyrinth zone-where oxygen and nutrients are exchanged between the mother and the fetus-consists of maternal and fetal blood vessels. Our results showed the labyrinth volume reduced in both females and males in a dose-dependent manner (Figure 3). As fetal capillary bed has endothelial cells while the maternal blood sinus has no endothelial cells, CD31 was used to identify the fetal capillary endothelial cells (Figure 4A). In addition, compared with the control group, the length and surface density of the fetal capillary significantly reduced in the PDE groups in a dose-dependent manner (Figure $4 B, C, \mathrm{P}<0.01$ ), and the reduction of the surface area of the fetal capillary was also dose-dependent (Figure 4D, $\mathrm{P}<0.01$ ). The fetal capillary length density, surface density and surface area of the male placenta was lower than that of the female placenta (Figure $4 B, C, D, \mathrm{P}<0.05)$.

\section{Changes in the oxygen diffusion capacity of the labyrinth zone after PDE}

The syncytial membrane thickness is a key physiological parameter of the placenta (26) and represents the diffusion distance of nutrients from the maternal blood to the fetal blood (27). The syncytial membrane is the main resistance to transplacental transport and the key determinant of oxygen diffusion capacity (28). Our results showed the syncytial membrane thickness increased significantly after PDE (Figure $5 A, B, C, \mathrm{P}<0.01$ ), and the theoretical diffusion capacity and the specific diffusion of oxygen dose-dependently reduced (Figure $5 D, E, \mathrm{P}<0.01$ ). Furthermore, after PDE, the oxygen diffusion capacity of male placenta were lower than that of female placenta 
A

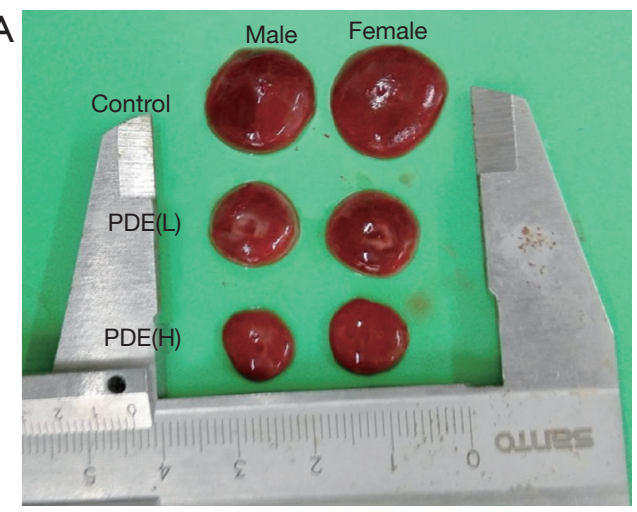

C

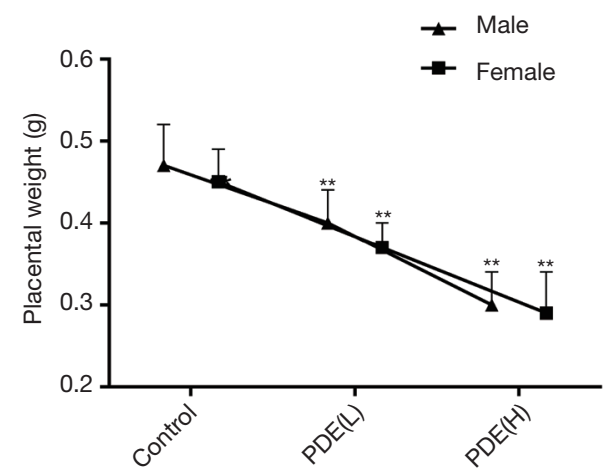

B
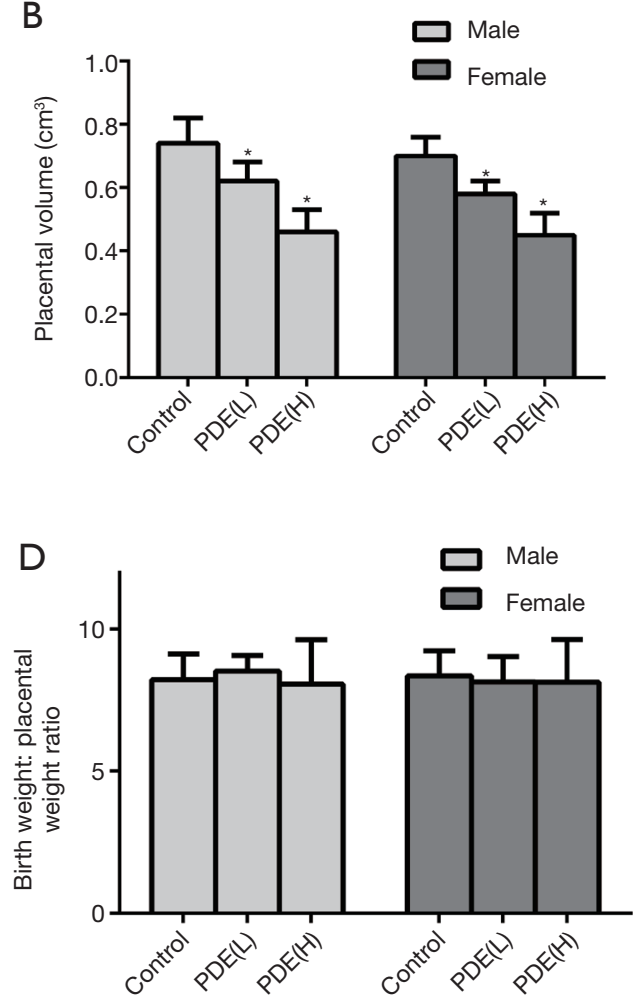

Figure 2 Effects of prenatal dexamethasone exposure (PDE) on the placental volume and weight. (A) The changes in the placental volume after PDE; (B) placental volume after PDE; (C) placental weight after PDE; (D) the ratio of birthweight to placental weight. Data are presented as mean \pm S.E.M., $\mathrm{n}=11$ in each group. ${ }^{*}, \mathrm{P}<0.05$, **, $\mathrm{P}<0.01$ vs. corresponding controls. PDE (L): $0.2 \mathrm{mg} / \mathrm{kg} \cdot \mathrm{d} ; \mathrm{PDE}$ (H): $0.8 \mathrm{mg} / \mathrm{kg} \cdot \mathrm{d}$.

(Figure 5D,E, $\mathrm{P}<0.05$ ). These results suggest that $\mathrm{PDE}$ can reduce oxygen diffusion capacity by increasing the thickness of the syncytial membrane.

\section{Changes in the placental nutrient transporters after PDE}

Nutrients such as glucose, amino acids, cholesterol, and others are transported across the placenta by transporters. To explore the effects of PDE on the transporters, the mRNA expression of placental nutrient transporters were detected. In the male group, the mRNA and protein expression of the cholesterol transporter (SRB1), amino acid transporter (LAT1) and triglyceride transporter (LPL) reduced significantly while placental glucose transporter (GLUT1 and GLUT3) have a decrease trend (Figure $6 A, B, C, \mathrm{P}<0.01$ ). The $\mathrm{mRNA}$ and protein expression of placental glucose transporter, cholesterol transporter, amino acid transporter, and triglyceride transporter increased in female group (Figure $6 D, E, F, \mathrm{P}<0.01$ ).

\section{Effects of PDE on placental IGF1/IGF2 expression}

IGF1 and IGF2 affect placental structure and functional development. IGF2 over-expression leads to the overgrowth of the placenta and fetus (29), while IGF1 increases the placental blood flow and nutrient transport by inhibiting the release of vasoconstrictors (30). Our results showed PDE reduced the placental IGF1 mRNA and protein expression in both female and male groups. But the mRNA and protein expression of IGF2 was significantly increased in female placentas while significantly decreased in male placentas (Figure $7, \mathrm{P}<0.01$ ).

\section{Discussion}

The National Institutes of Health (NIH) recommends giving an intramuscular injection of dexamethasone $6 \mathrm{mg}$ every 12 hours for a total of 4 times to pregnant women at risk of preterm labor before 34 weeks $(31,32)$. However, 
A
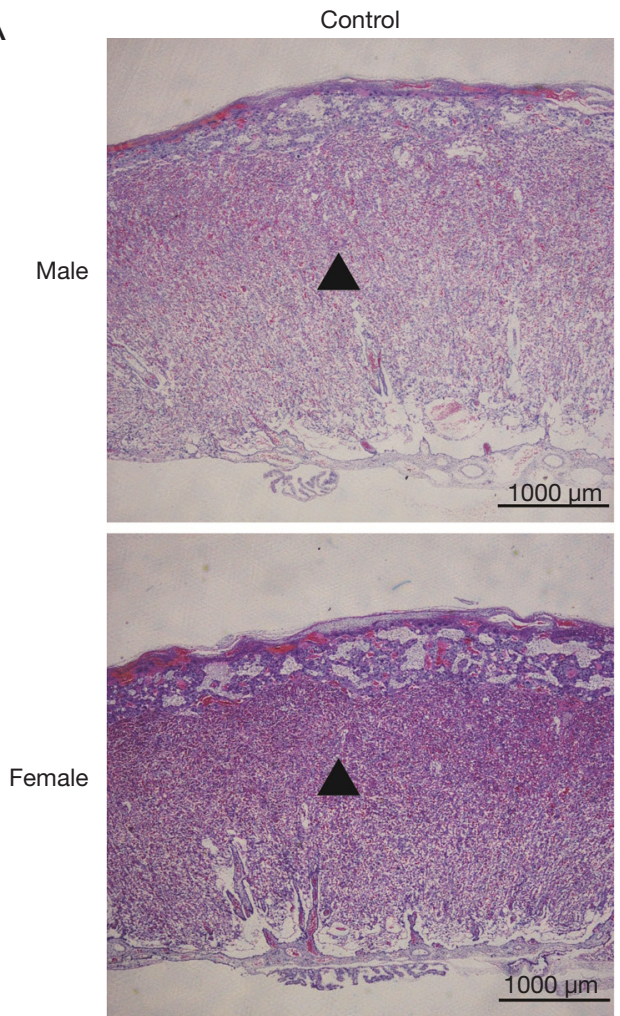

PDE (L)
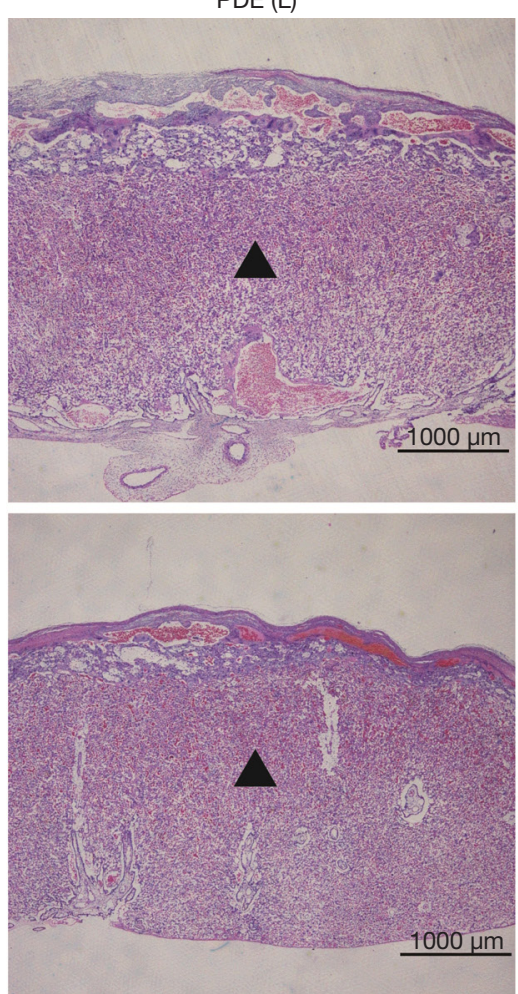

PDE $(H)$
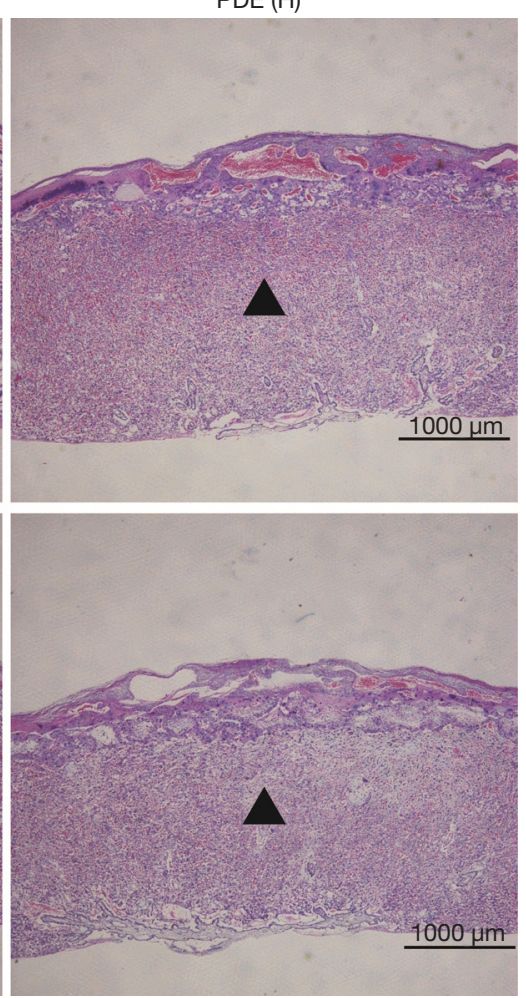

B

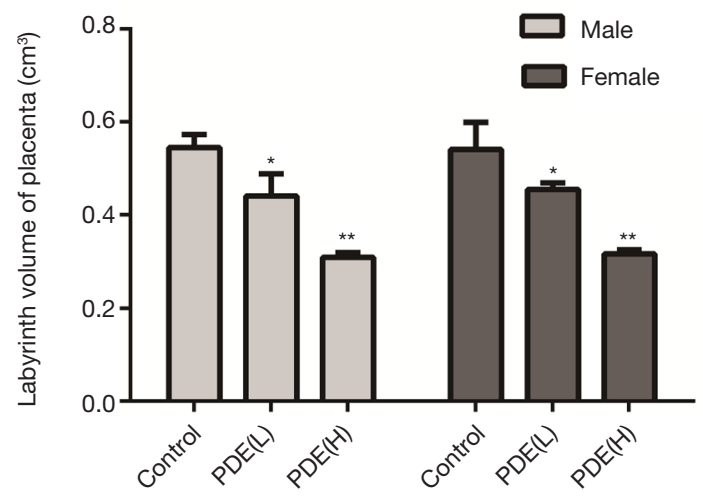

Figure 3 Effects of prenatal dexamethasone exposure (PDE) on the placental labyrinth volume. (A) Measurement of labyrinth volume on H\&E-stained sections $(\times 200)$. Black triangle: labyrinth. (B) Placental labyrinth volume. Data are presented as mean \pm S.E.M., $\mathrm{n}=11$ in each group. *, $\mathrm{P}<0.05$, ${ }^{* *}, \mathrm{P}<0.01$ vs. corresponding controls. PDE (L): $0.2 \mathrm{mg} / \mathrm{kg} \cdot \mathrm{d}$; PDE (H): $0.8 \mathrm{mg} / \mathrm{kg} \cdot \mathrm{d}$.

the pros and cons of glucocorticoid therapy for pregnant women who are at risk of preterm delivery at 34 to 37 weeks have not been definitively determined or reported. The dose is equivalent to $0.2 \mathrm{mg} / \mathrm{kg} \cdot \mathrm{d}$ for an adult weighing about $60 \mathrm{~kg}$. According to the dose conversion between human and rat (human: rat $=1: 6.17$ ) (33), the dose of the above-mentioned pregnant women was equivalent to the dose of $1.234 \mathrm{mg} / \mathrm{kg} \cdot \mathrm{d}$ in the rats. Therefore, both 0.2 and
$0.8 \mathrm{mg} / \mathrm{kg} \cdot \mathrm{d}$ dexamethasone can be achieved clinically. We chose 0.2 and $0.8 \mathrm{mg} / \mathrm{kg} \cdot \mathrm{d}$ to investigate the dosedependent relationship between prenatal dexamethasone exposure and placental injury.

The dose we chose was smaller than the actual clinical dose. However, even at this dose, a dose-dependent decrease in placental nutrient transport capacity and oxygen dispersion capacity was observed. Therefore, this study 
A
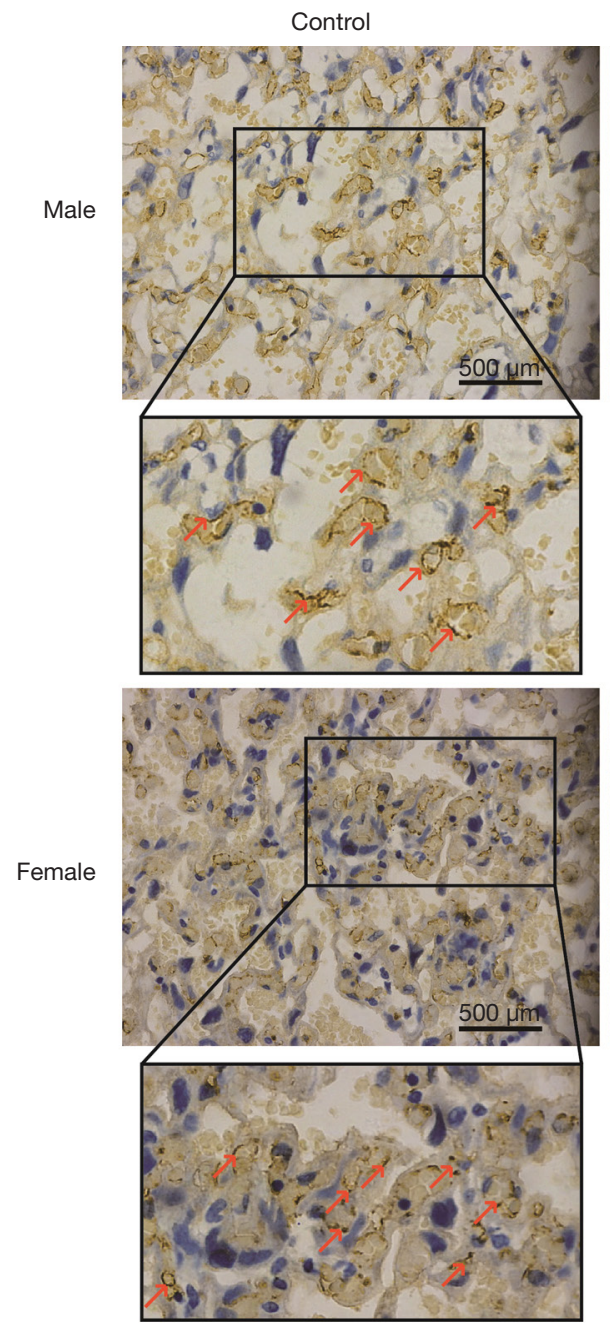

PDE (L)
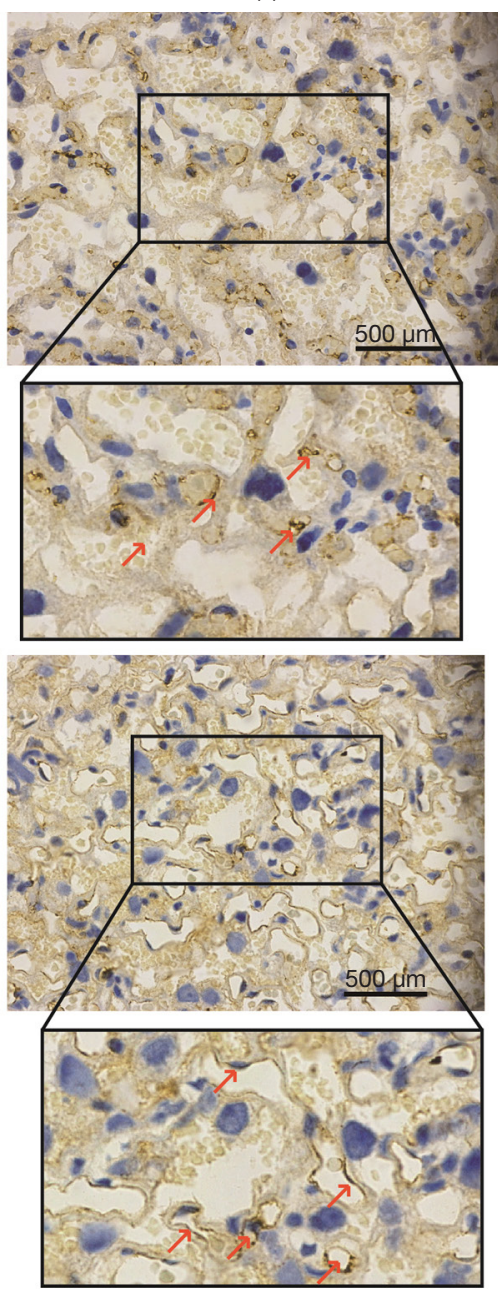

$\operatorname{PDE}(\mathrm{H})$
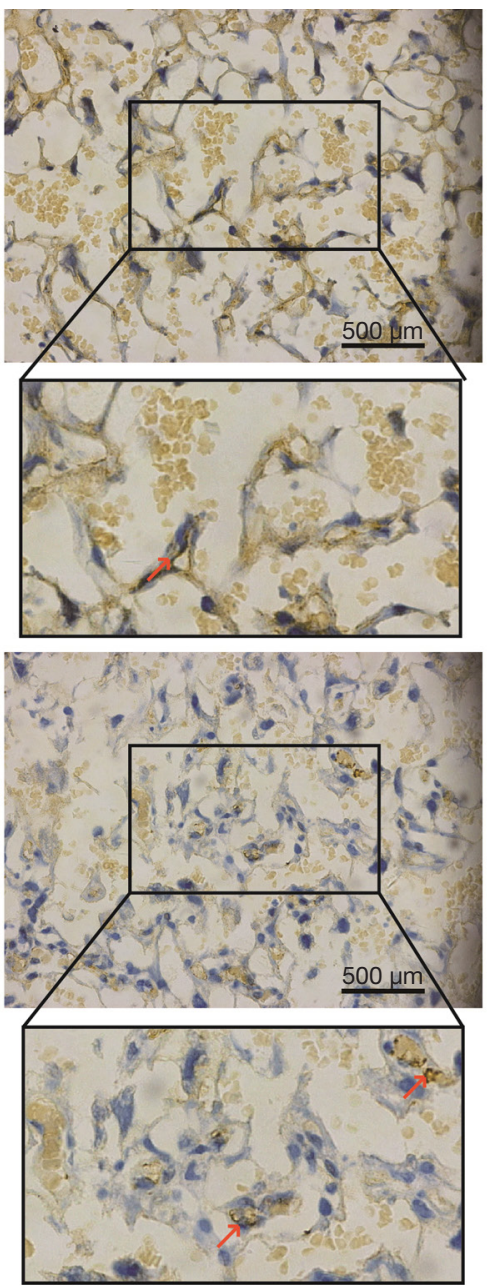

B

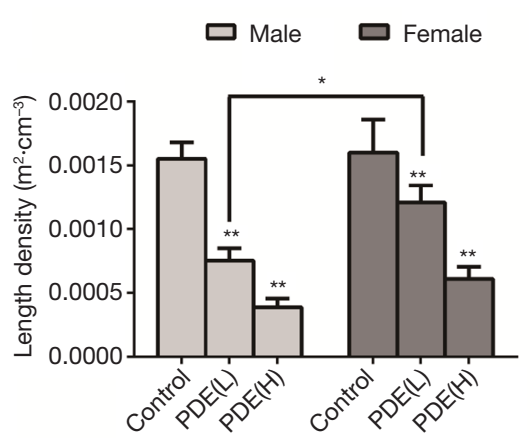

C

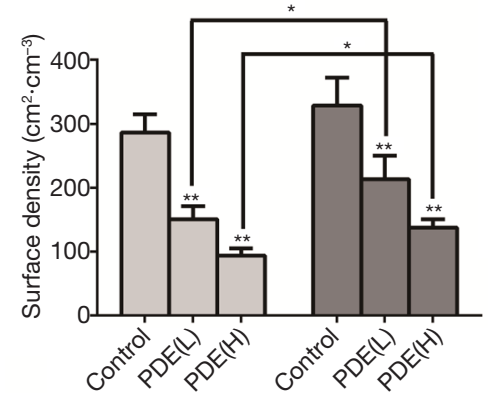

D

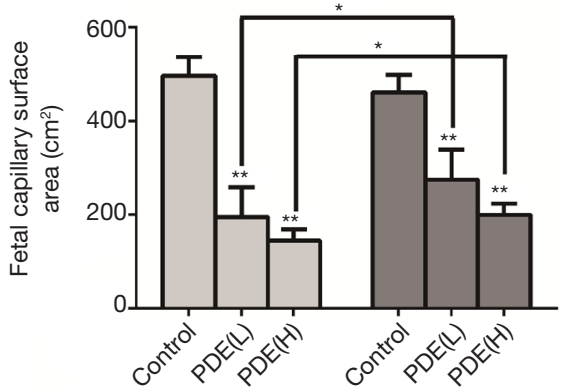

Figure 4 Effects of prenatal dexamethasone exposure (PDE) on the placental villous capillaries. (A) Villous capillaries with CD31 expression in the placental labyrinth zone ( $\times 400)$. Red arrow: villous capillaries. (B) Length density, (C) surface density, (D) fetal capillary surface area. Data are presented as the mean \pm S.E.M., $\mathrm{n}=11$ in each group. ${ }^{*}, \mathrm{P}<0.05,{ }^{* *}, \mathrm{P}<0.01$ vs. corresponding controls. PDE (L): $0.2 \mathrm{mg} / \mathrm{kg} \cdot \mathrm{d}$; PDE (H): $0.8 \mathrm{mg} / \mathrm{kg} \cdot \mathrm{d}$. 
A

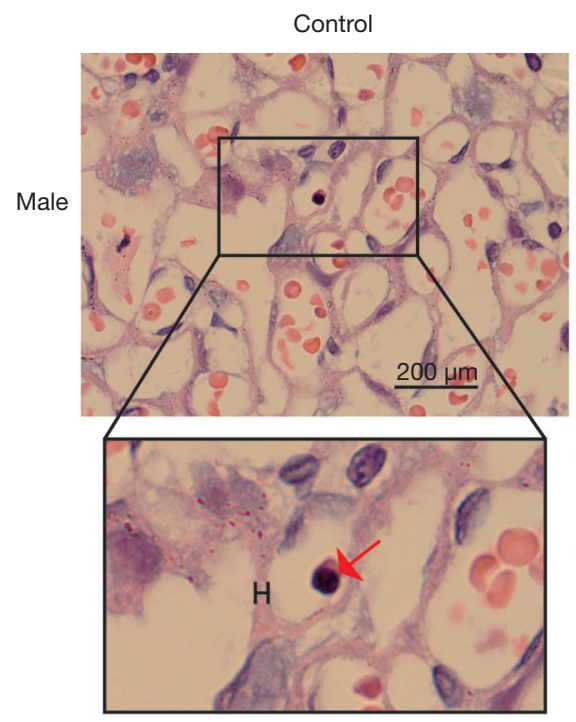

B

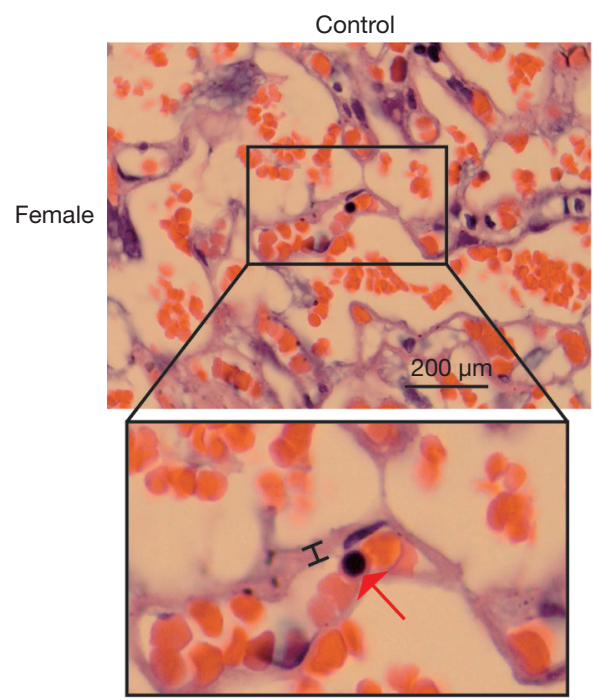

C

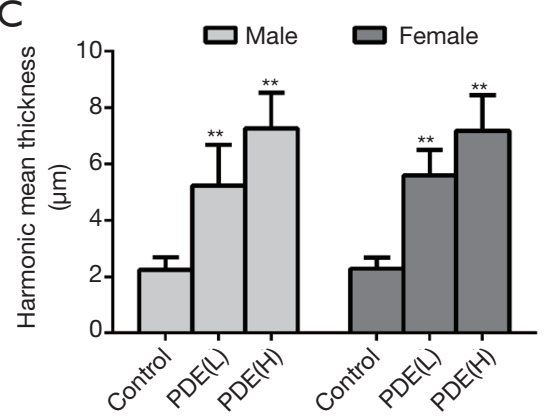

PDE (L)

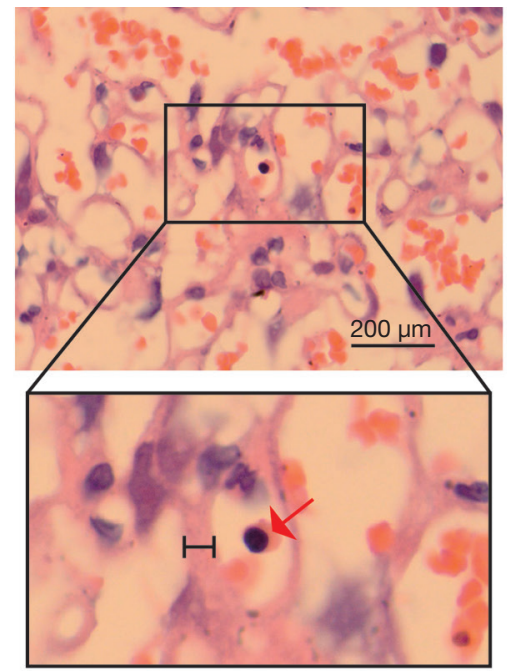

PDE (L)

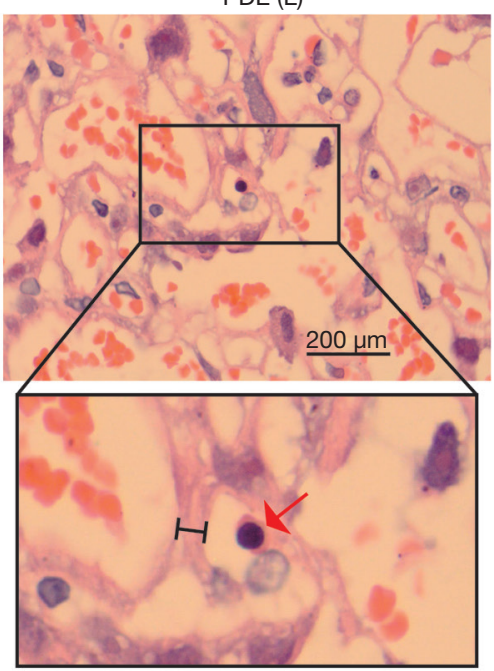

D

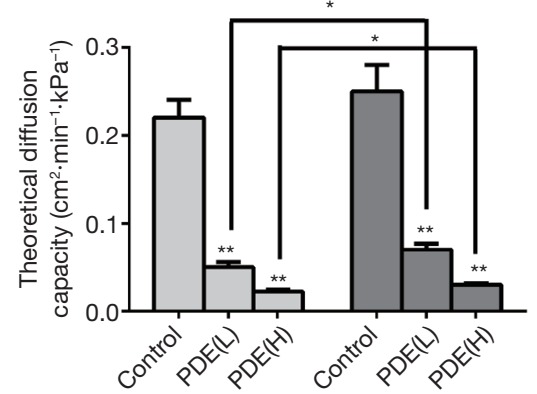

$\operatorname{PDE}(\mathrm{H})$

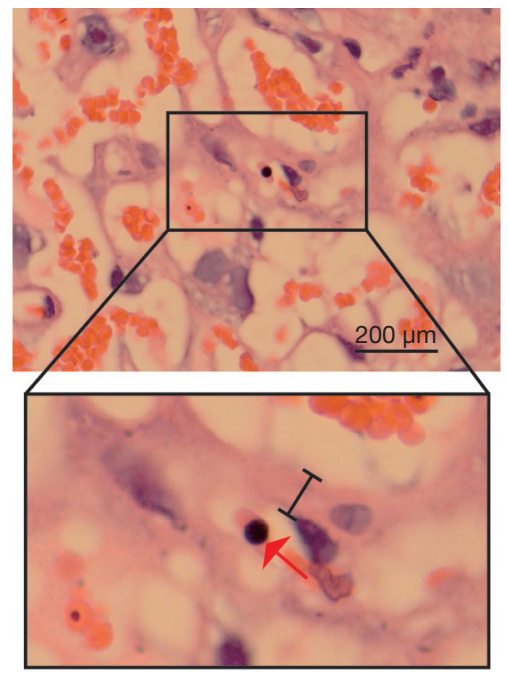

$\operatorname{PDE}(\mathrm{H})$

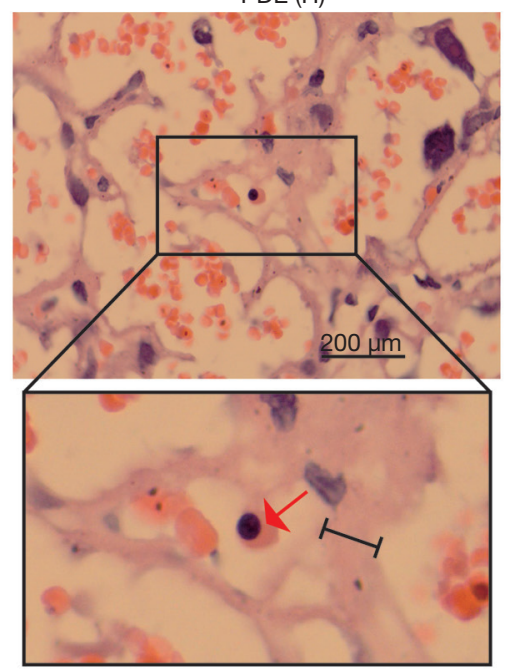

E

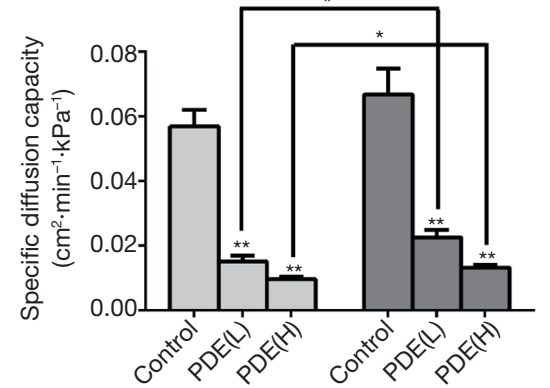

Figure 5 Effects of prenatal dexamethasone exposure (PDE) on the mean harmonic thickness and oxygen diffusion capacity. Sections from male placenta (A) and female placenta (B). H\&E-stained vertical sections $(\times 100)$. Red arrow: fetal nucleated erythrocytes. Black line: mean harmonic thickness. Mean harmonic thickness (C), theoretical diffusion capacity (D) and specific diffusion capacity (E). Data are presented as the mean \pm S.E.M., $\mathrm{n}=11$ in each group. ${ }^{*}, \mathrm{P}<0.05,{ }^{* *}, \mathrm{P}<0.01$ vs. corresponding controls. $\mathrm{PDE}(\mathrm{L}): 0.2 \mathrm{mg} / \mathrm{kg} \cdot \mathrm{d} ; \mathrm{PDE}(\mathrm{H}): 0.8 \mathrm{mg} / \mathrm{kg} \cdot \mathrm{d}$. 
A

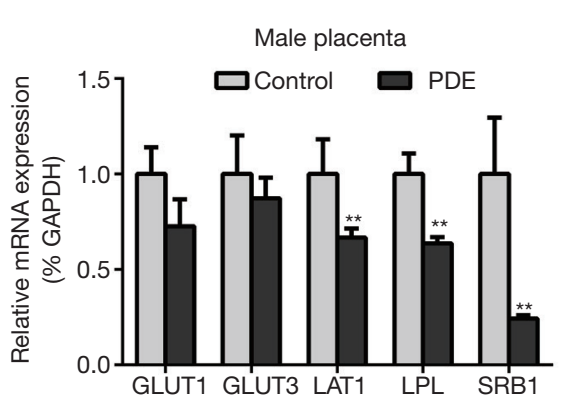

D

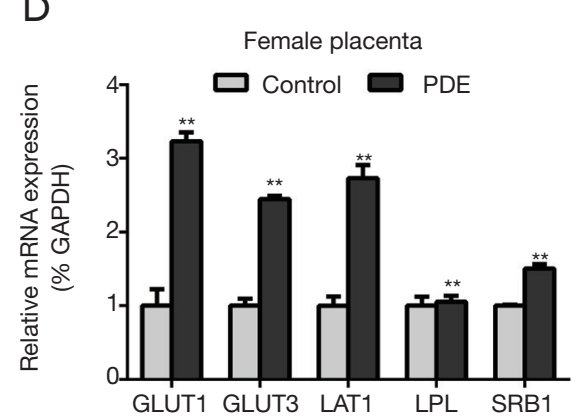

B

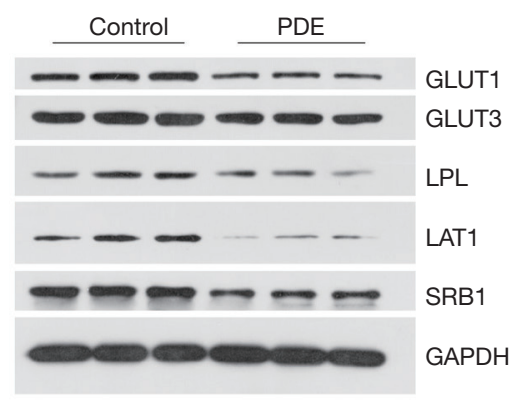

$E$

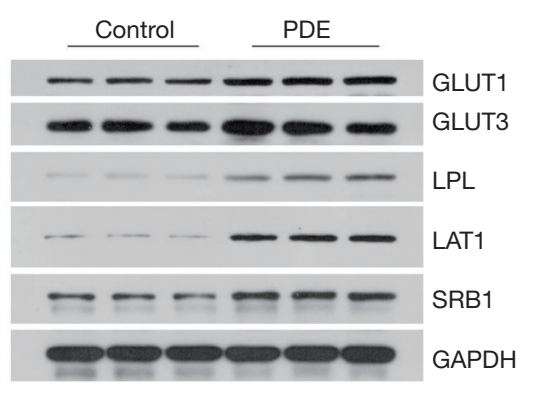

C

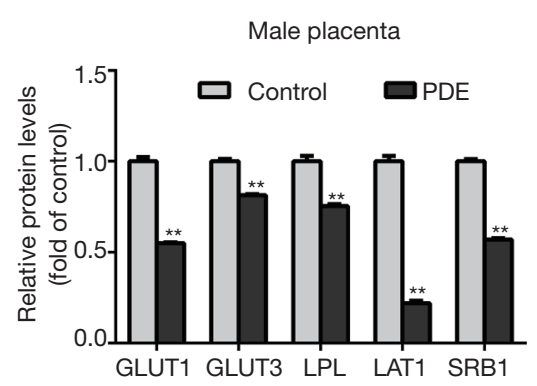

$\mathrm{F}$

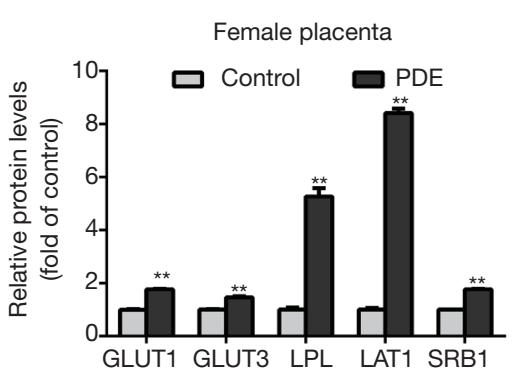

Figure 6 Effects of prenatal dexamethasone exposure (PDE) on placental transporter. The mRNA and protein expression of placental glucose transporter 1 (GULT1), glucose transporter 3 (GLUT3), lipoprotein lipase (LPL), scavenger receptor class B type 1 (SRB1), L-type amino acid transporter 1 (LAT1) was detected by RT-qPCR and western blotting respectively. (A,B,C): Male placenta. (D,E,F): Female placenta. Data are presented as mean \pm S.E.M., $\mathrm{n}=11$ for RT-qPCR and $\mathrm{n}=3$ for protein assay in each group. ${ }^{* *}, \mathrm{P}<0.01$ vs. corresponding controls. PDE: $0.2 \mathrm{mg} / \mathrm{kg} \cdot \mathrm{d}$.

may suggest that clinical obstetricians should minimize the unnecessary use of prenatal dexamethasone and strengthen the monitoring of fetal safety in utero for those who must use dexamethasone.

In this study, our results showed PDE decreased the fetal weight and increased the IUGR rate in dose-dependent manners. Meanwhile, the placental structure and the gene expression of transporters dose-dependently changed after $\mathrm{PDE}$, and the theoretical diffusion capacity and the specific diffusion of oxygen dose-dependently reduced, and the reduction in the male group was more evident than in the female group. These findings indicate that PDE might cause fetal hypoxia and IUGR by reducing placental oxygen and nutrient transport capacity, the outcomes of which were dependent on fetal sex.

In a majority of studies, only placental weight, placenta volume or birthweight: placental weight ratio are used as the indicator of placental efficiency (34). Our present study indicated that these factors provide only a rough estimate of placental development and do not differentiate the development of individual compartments, and they are also not accurately reflect the function of the placenta. For example, in our previous (10) and the current studies, PDE caused fetal growth retardation, but the birthweight: placental weight ratio was not affected by PDE, and there were no significant differences in the placental weight and placenta volume between the males and females. Cuffe et al. (35) found that corticosterone exposure had no effect on the stereological measurement of placental volume in male and female placentas, however, the volume of male labyrinth placenta decreased by $17 \%$. In the present study, the stereological analysis showed PDE reduced the labyrinth volume, dose-dependently declined the length and density of fetal capillaries, and eventually reduced the surface area of fetal capillaries, and the decrease was more evident in the males than in the females. In addition, the syncytial membrane thickness increased significantly after PDE.

Oxygen transfers across the placenta via simple diffusion. 
A

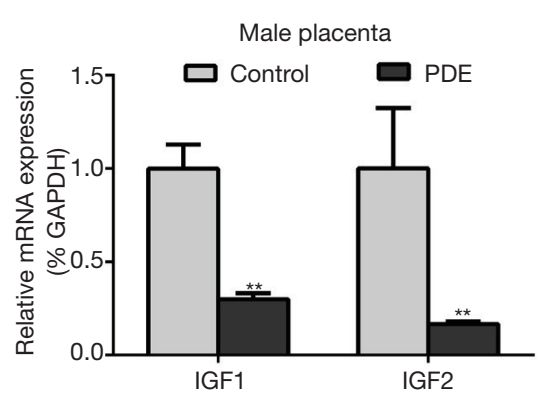

D

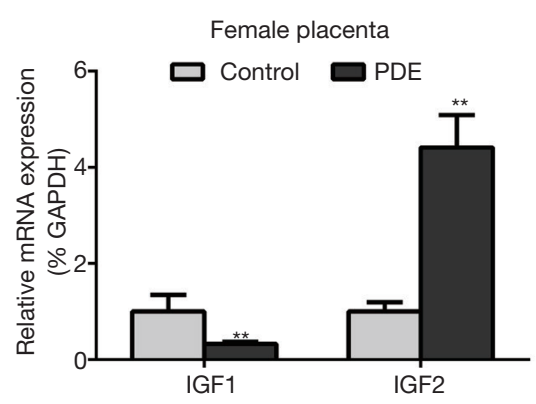

B

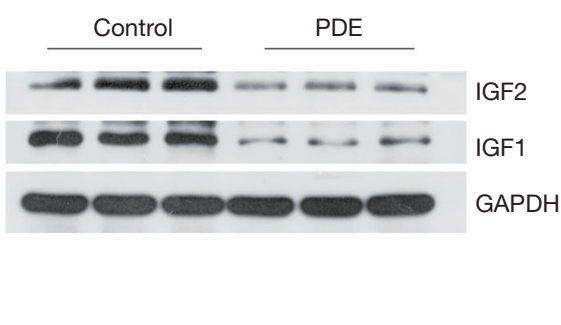

E

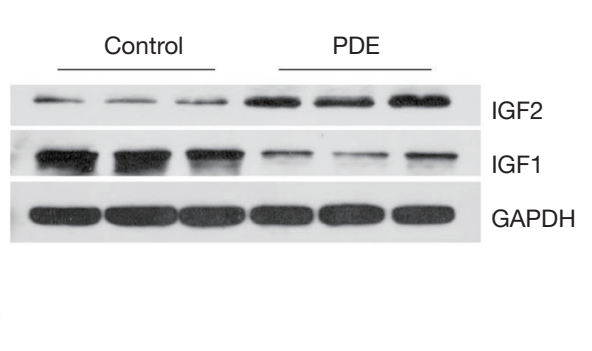

C

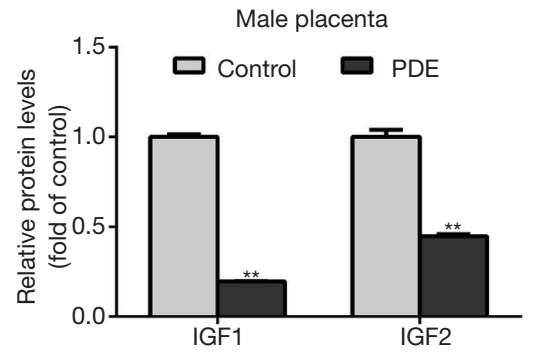

$\mathrm{F}$

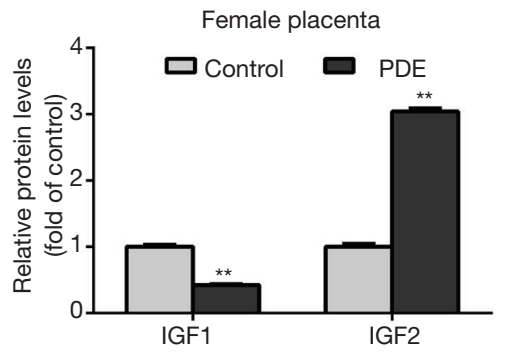

Figure 7 Effects of prenatal dexamethasone exposure (PDE) on placental IGF1/IGF2 expression. The mRNA and protein expression of placental IGF1/IGF2 was detected by RT-qPCR and western blotting respectively. (A,B,C) Male placenta. (D,E,F) Female placenta. Data are presented as mean \pm S.E.M., $\mathrm{n}=11$ for RT-qPCR and $\mathrm{n}=3$ for protein assay in each group. ${ }^{* *}, \mathrm{P}<0.01 v$ s. corresponding controls. PDE: $0.2 \mathrm{mg} / \mathrm{kg} \cdot \mathrm{d}$.

The surface area of fetal capillaries and the interhemal membrane thickness are important factors in assessing the placental oxygen diffusion capacity (36). The syncytial membrane thickness exerts a greater effect on oxygen transport than the surface area of fetal capillaries. Even mild increase in the syncytial membrane thickness may weaken the placental oxygen diffusion capacity significantly, which can not be induced by the change in the surface area (28). In the present study, theoretical oxygen diffusion capacity was calculated using the Krogh diffusion coefficient, but the estimate was not equal to the actual oxygen diffusion capacity because the oxygen disassociation from maternal erythrocytes, oxygen uptake by the fetus, and plasma intervention were not considered (37). The specific diffusion capacity is an estimate of the oxygen diffusion capacity in terms of fetal requirements, obtained by theoretical oxygen diffusion capacity/fetal weight (38). In this study, theoretical oxygen diffusion dose-dependently decreases in males and females. However, because male fetuses are heavier than females, the specific diffusion ability of male fetuses is lower than that of females, which means that males suffer from more severe hypoxia. Furthermore, lactic is a well-known indicator of hypoxia. In our previous study, serum metabolic profile analysis indicated that PDE increases serum lactic in male and female fetus (our lab unpublished data). The above findings suggest that PDE could cause fetal hypoxia by decreasing placental oxygen diffusion capacity.

A significant amount of nutrients are transferred across the placental barrier via passive diffusion (17). Glucose, amino acids, cholesterol, and fatty acids are passively transported via the transporters in the placental trophoblast. Glucose is the most important substrate for fetal energy metabolism, while placental transportation is the only supply for the fetus (39). Glucose transport across the placenta by carrier-mediated diffusion. GLUT1 and GLUT3 are main isoforms of glucose transporters expressed in placenta (40). Impaired placental glucose transport has been regarded as a pathophysiological mechanism of IUGR (39). However, Jansson et al. (41) reported that the protein expression and activity of GLUT1 remained unchanged in the IUGR placentas. Janzen et al. (40) performed immunohistochemical studies on the IUGR 
placentas and found that GLUT3 expression significantly increased. Langdown et al. (42) have shown that the protein expression of placental GLUT1 and GLUT3 increased in a compensatory manner to mitigate the fetal growth retardation induced by dexamethasone. In this study, the mRNA and protein expression of GLUT1 and GLUT3 showed a higher expression level in female group after PDE, whereas there were a lower expression trend in male group after PDE. However, the statistically significant difference was not observed, that may be attributable to the relative small number of subjects studied.

Similarly, amino acid, cholesterol and fatty acid are indispensable in the development of embryo and fetus. Amino acid play a key role in fetal tissue development. Fatty acids are absolutely necessary for fetal brain development and fat accretion. Cholesterol plays an important role in the development of fetus because it is an important component of cell membrane and a substrate of steroid hormones (43). During pregnancy, these nutrients depend on maternal transport. Reduction of nutrient transport caused by various factors will have adverse effects on fetal development. LAT1 transports the essential neutral amino acids to the fetus (44). SRB1 mediates transplacental cholesterol transport (45). LPL is responsible for triglycerides transport. Studies have shown that in the IUGR placentas the expression of amino acid transporters reduced (46); and the activity of lipoprotein transporter LPL also reduced (47), while the mRNA and protein expression of LPL was up-regulated as a compensation (48); the mRNA expression of the cholesterol transporter SRB1 reduced (49). In our present study, the mRNA and protein expression of LAT1, LPL, SRB1 mRNA was decreased in a dose-dependent manner after PDE in male placenta and compensated increased in lowdose group in female placenta, while remained unchanged in high-dose group in female placenta. It was found that IUGR fetus showed lower concentrations of glucose, cholesterol, albumin (50) and long-chain polyunsaturated fatty acids (51) compared to normal ones. The transport capacity of placenta for the above nutrients is decided by transport area, the number of transporters and the transport distance (interhemal membrane thickness). These findings suggest that PDE may decrease the transportation capacity of placenta through decreasing these three factors in males, while in females, the decrease was contributed to the reduction of transport area and increment of interhemal membrane thickness. We infer that the increase of transporter could not compensate for the decrease of transport capacity caused by the transport area and distance in low-dose group of females.

To further figure out the underlying mechanism of sex difference, the expression of IGF1 and IGF2 mRNA were detected. IGF1 may regulate placental nutritional capacity, stimulates the intake of glucose and amino acids, promote the intake and metabolism of placental nutrition, increase placental blood flow and provide nutrition for fetal growth (52). The placental growth as well as fetal growth, is also promoted by the paternally expressed imprinted genes IGF2. Placental IGF2 could increase the placental labyrinth volume and trophoblast surface area, reduce the interhemal membrane thickness (53), and regulate the expression of nutrient transporters (54). In the present study, after PDE, the placental IGF2 expression increase in female group but it decreased in male groups. This is consistent with the nutrient transporter expression. However, there is no sex difference of IGF1 expression. Thus, we speculate that imprinted gene IGF2 increases the expression of nutrient transporters in low-dose female group. It also alleviates PDE-induced placenta structure damage in females to some extent. The sex difference in the placental nutrient transport capacity after PDE may be due to the difference in the expression of IGF2. Nevertheless, further exploration is needed to verify this hypothesis which is also the major limitation of our study.

\section{Conclusions}

Our study for the first time showed that PDE can cause fetal hypoxia and IUGR. The underlying mechanism may be explained as that dexamethasone can reduce the placental oxygen and nutrient transport capacity. There is a sex difference to this damage, which may be related to the difference in the IGF2 expression after PDE (Figure 8). These results remind us that clinicians should reduce unnecessary applications of dexamethasone during pregnancy, especially for those whose fetus suffers from potential anoxia or in IUGR. In the future, more explorations are needed for the molecular mechanism by which PDE alters the placental structure and the transporter expression. 


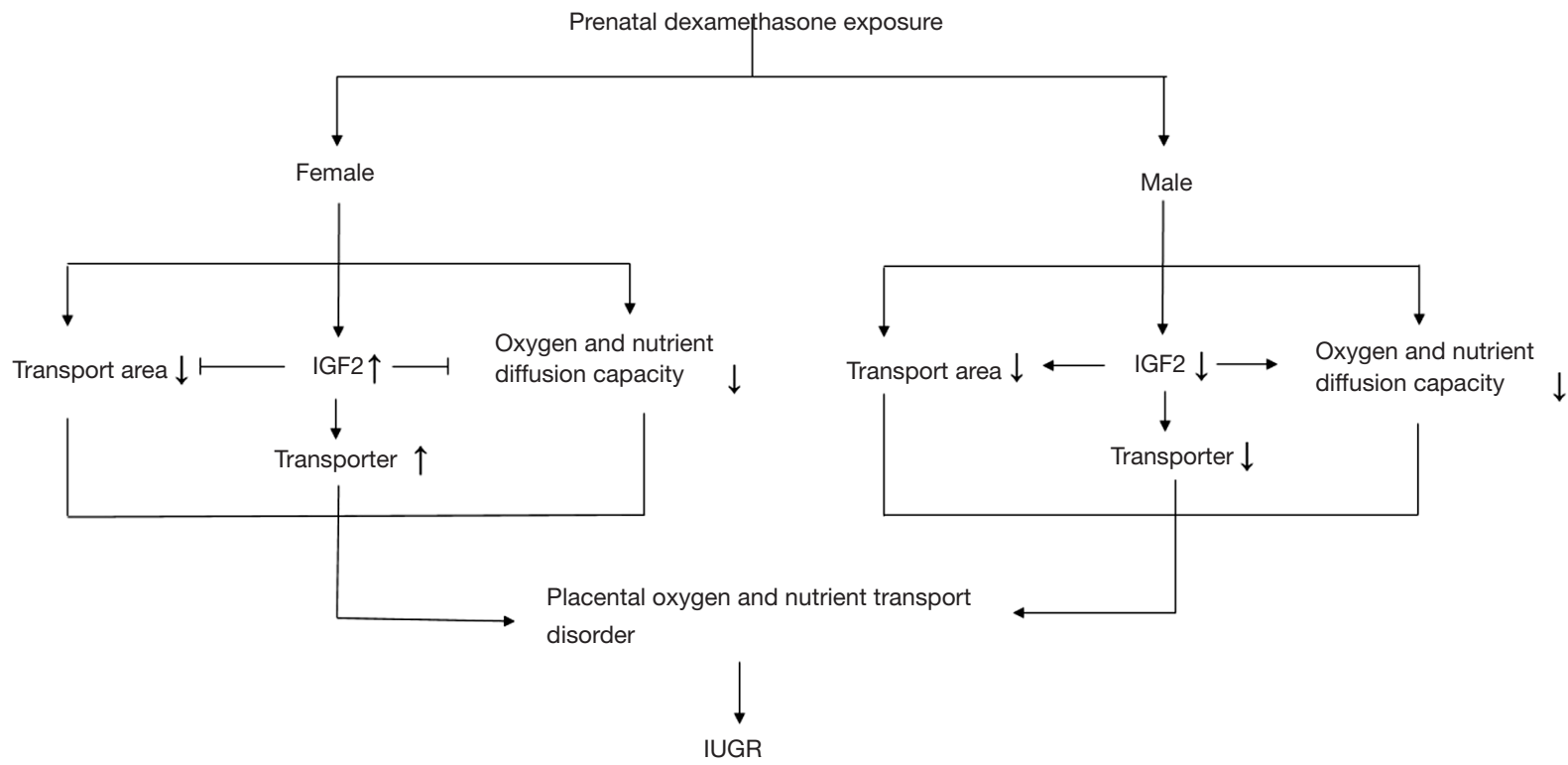

Figure 8 Potential mechanism of placental nutrient transport disorder after PDE. IUGR, intrauterine growth retardation.

\section{Acknowledgments}

Funding: This study was supported by grants from Medical Science Advancement Program (Basic Medical Sciences) of Wuhan University (Grant No. TFJC2018001).

\section{Footnote}

Conflicts of Interest: The authors have no conflicts of interest to declare.

Ethical Statement: The authors are accountable for all aspects of the work in ensuring that questions related to the accuracy or integrity of any part of the work are appropriately investigated and resolved. This study has been approved by the Ethics Committee of Zhongnan Hospital of Wuhan University.

Open Access Statement: This is an Open Access article distributed in accordance with the Creative Commons Attribution-NonCommercial-NoDerivs 4.0 International License (CC BY-NC-ND 4.0), which permits the noncommercial replication and distribution of the article with the strict proviso that no changes or edits are made and the original work is properly cited (including links to both the formal publication through the relevant DOI and the license). See: https://creativecommons.org/licenses/by-nc-nd/4.0/.

\section{References}

1. Roberts D, Dalziel S. Antenatal corticosteroids for accelerating fetal lung maturation for women at risk of preterm birth. Cochrane Database Syst Rev 2006;(3):CD004454.

2. Effect of corticosteroids for fetal maturation on perinatal outcomes. NIH Consensus Development Panel on the Effect of Corticosteroids for Fetal Maturation on Perinatal Outcomes. JAMA 1995;273:413-8.

3. Jobe AH, Soll RF. Choice and dose of corticosteroid for antenatal treatments. Am J Obstet Gynecol 2004;190:878-81.

4. Slattery MM, Morrison JJ. Preterm delivery. Lancet 2002;360:1489-97.

5. Long NM, Ford SP, Nathanielsz PW. Multigenerational effects of fetal dexamethasone exposure on the hypothalamic-pituitary-adrenal axis of first- and secondgeneration female offspring. Am J Obstet Gynecol 2013;208:217.e1-8.

6. Romo A, Carceller R, Tobajas J. Intrauterine growth retardation (IUGR): epidemiology and etiology. Pediatr Endocrinol Rev 2009;6 Suppl 3:332-6.

7. Pallotto EK, Kilbride HW. Perinatal outcome and later implications of intrauterine growth restriction. Clin Obstet Gynecol 2006;49:257-69.

8. Dall'Asta A, Brunelli V, Prefumo F, et al. Early onset fetal growth restriction. Matern Health Neonatol Perinatol 2017;3:2. 
9. Silver RM. Examining the link between placental pathology, growth restriction, and stillbirth. Best Pract Res Clin Obstet Gynaecol 2018;49:89-102.

10. Xu D, Chen M, Pan XL, et al. Dexamethasone induces fetal developmental toxicity through affecting the placental glucocorticoid barrier and depressing fetal adrenal function. Environ Toxicol Pharmacol 2011;32:356-63.

11. Miller SL, Chai M, Loose J, et al. The effects of maternal betamethasone administration on the intrauterine growthrestricted fetus. Endocrinology 2007;148:1288-95.

12. Murphy VE, Smith R, Giles WB, et al. Endocrine regulation of human fetal growth: the role of the mother, placenta, and fetus. Endocr Rev 2006;27:141-69.

13. Sibley CP, Turner MA, Cetin I, et al. Placental phenotypes of intrauterine growth. Pediatr Res 2005;58:827-32.

14. Watson ED, Cross JC. Development of structures and transport functions in the mouse placenta. Physiology (Bethesda) 2005;20:180-93.

15. Cross JC, Simmons DG, Watson ED. Chorioallantoic morphogenesis and formation of the placental villous tree. Ann N Y Acad Sci 2003;995:84-93.

16. Adamson SL, Lu Y, Whiteley KJ, et al. Interactions between trophoblast cells and the maternal and fetal circulation in the mouse placenta. Dev Biol 2002;250:358-73.

17. Sibley CP, Coan PM, Ferguson-Smith AC, et al. Placentalspecific insulin-like growth factor 2 (Igf2) regulates the diffusional exchange characteristics of the mouse placenta. Proc Natl Acad Sci U S A 2004;101:8204-8.

18. Howard CV, Reed MG. Unbiased stereology: Threedimensional measurement in microscopy. Oxford: BIOS, 1998.

19. Ao Y, Sun Z, Hu S, et al. Low functional programming of renal AT2R mediates the developmental origin of glomerulosclerosis in adult offspring induced by prenatal caffeine exposure. Toxicol Appl Pharmacol 2015;287:128-38.

20. Yang ZW, Qin YH, Su SR. Use of star volume to measure the size of the alveolar space in the asthmatic guinea-pig lung. Respirology 2002; 7:117-21.

21. Baddeley AJ, Gundersen HJ, Cruz-Orive LM. Estimation of surface area from vertical sections. J Microsc 1986;142:259-76.

22. Jensen EB, Gundersen HJ, Osterby R. Determination of membrane thickness distribution from orthogonal intercepts. J Microsc 1979;115:19-33.

23. Tan Y, Liu J, Deng Y, et al. Caffeine-induced fetal rat over-exposure to maternal glucocorticoid and histone methylation of liver IGF-1 might cause skeletal growth retardation. Toxicol Lett 2012;214:279-87.

24. Lopez-Tello J, Jimenez-Martinez MA, Herrera EA, et al. Progressive uterine artery occlusion in the Guinea pig leads to defects in placental structure that relate to fetal growth. Placenta 2018;72-73:36-40.

25. Papastefanou I, Chrelias C, Siristatidis C, et al. Placental volume at 11 to 14 gestational weeks in pregnancies complicated with fetal growth restriction and preeclampsia. Prenat Diagn 2018;38:928-35.

26. Coan PM, Ferguson-Smith AC, Burton GJ. Developmental dynamics of the definitive mouse placenta assessed by stereology. Biol Reprod 2004;70:1806-13.

27. Demir R, Demir AY, Yinanc M. Structural changes in placental barrier of smoking mother. A quantitative and ultrastructural study. Pathol Res Pract 1994;190:656-67.

28. Mayhew TM, Jackson MR, Haas JD. Microscopical morphology of the human placenta and its effects on oxygen diffusion: a morphometric model. Placenta 1986;7:121-31.

29. Ferguson-Smith AC, Cattanach BM, Barton SC, et al. Embryological and molecular investigations of parental imprinting on mouse chromosome 7. Nature 1991;351:667-70.

30. Siler-Khodr TM, Forman J, Sorem KA. Doserelated effect of IGF-I on placental prostanoid release. Prostaglandins 1995;49:1-14.

31. American College of O, Gynecologists Committee on Obstetric P. ACOG Committee Opinion No. 402: Antenatal corticosteroid therapy for fetal maturation. Obstet Gynecol 2008;111:805-7.

32. Haram K, Mortensen JH, Magann EF, et al. Antenatal corticosteroid treatment: factors other than lung maturation. J Matern Fetal Neonatal Med 2017;30:1437-41.

33. Reagan-Shaw S, Nihal M, Ahmad N. Dose translation from animal to human studies revisited. FASEB J 2008;22:659-61.

34. Hayward CE, Lean S, Sibley CP, et al. Placental Adaptation: What Can We Learn from Birthweight:Placental Weight Ratio? Front Physiol 2016;7:28.

35. Cuffe JS, O'Sullivan L, Simmons DG, et al. Maternal corticosterone exposure in the mouse has sex-specific effects on placental growth and mRNA expression. Endocrinology 2012;153:5500-11.

36. Woods L, Perez-Garcia V, Hemberger M. Regulation of Placental Development and Its Impact on Fetal Growth- 
New Insights From Mouse Models. Front Endocrinol (Lausanne) 2018;9:570.

37. Gundersen HJ, Bendtsen TF, Korbo L, et al. Some new, simple and efficient stereological methods and their use in pathological research and diagnosis. APMIS 1988;96:379-94.

38. Mayhew TM, Sorensen FB, Klebe JG, et al. Oxygen diffusive conductance in placentae from control and diabetic women. Diabetologia 1993;36:955-60.

39. Jansson T, Wennergren M, Illsley NP. Glucose transporter protein expression in human placenta throughout gestation and in intrauterine growth retardation. J Clin Endocrinol Metab 1993;77:1554-62.

40. Janzen C, Lei MY, Cho J, et al. Placental glucose transporter 3 (GLUT3) is up-regulated in human pregnancies complicated by late-onset intrauterine growth restriction. Placenta 2013;34:1072-8.

41. Jansson T, Ylven K, Wennergren M, et al. Glucose transport and system A activity in syncytiotrophoblast microvillous and basal plasma membranes in intrauterine growth restriction. Placenta 2002;23:392-9.

42. Langdown ML, Sugden MC. Enhanced placental GLUT1 and GLUT3 expression in dexamethasoneinduced fetal growth retardation. Mol Cell Endocrinol 2001;185:109-17.

43. Brett KE, Ferraro ZM, Yockell-Lelievre J, et al. Maternalfetal nutrient transport in pregnancy pathologies: the role of the placenta. Int J Mol Sci 2014;15:16153-85.

44. Verrey F, Closs EI, Wagner CA, et al. CATs and HATs: the SLC7 family of amino acid transporters. Pflugers Arch 2004;447:532-42.

45. Larque E, Ruiz-Palacios M, Koletzko B. Placental regulation of fetal nutrient supply. Curr Opin Clin Nutr Metab Care 2013;16:292-7.

46. Norberg S, Powell TL, Jansson T. Intrauterine growth

Cite this article as: Guo J, Fang M, Zhuang S, Qiao Y, Huang W, Gong Q, Xu D, Zhang Y, Wang H. Prenatal dexamethasone exposure exerts sex-specific effect on placental oxygen and nutrient transport ascribed to the differential expression of IGF2. Ann Transl Med 2020;8(5):233. doi: 10.21037/atm.2019.12.156 restriction is associated with a reduced activity of placental taurine transporters. Pediatr Res 1998;44:233-8.

47. Magnusson AL, Waterman IJ, Wennergren M, et al. Triglyceride hydrolase activities and expression of fatty acid binding proteins in the human placenta in pregnancies complicated by intrauterine growth restriction and diabetes. J Clin Endocrinol Metab 2004;89:4607-14.

48. Gauster M, Hiden U, Blaschitz A, et al. Dysregulation of placental endothelial lipase and lipoprotein lipase in intrauterine growth-restricted pregnancies. J Clin Endocrinol Metab 2007;92:2256-63.

49. Zhang G, Zhou J, Huang W, et al. Placental mechanism of prenatal nicotine exposure-reduced blood cholesterol levels in female fetal rats. Toxicol Lett 2018;296:31-8.

50. Nieto-Diaz A, Villar J, Matorras-Weinig R, et al. Intrauterine growth retardation at term: association between anthropometric and endocrine parameters. Acta Obstet Gynecol Scand 1996;75:127-31.

51. Assumpcao RP, Mucci DB, Fonseca FCP, et al. Fatty acid profile of maternal and fetal erythrocytes and placental expression of fatty acid transport proteins in normal and intrauterine growth restriction pregnancies. Prostaglandins Leukot Essent Fatty Acids 2017;125:24-31.

52. Sferruzzi-Perri AN, Owens JA, Pringle KG, et al. Maternal insulin-like growth factors-I and -II act via different pathways to promote fetal growth. Endocrinology 2006; 147:3344-55

53. Coan PM, Fowden AL, Constancia M, et al. Disproportional effects of Igf2 knockout on placental morphology and diffusional exchange characteristics in the mouse. J Physiol 2008;586:5023-32.

54. Matthews JC, Beveridge MJ, Dialynas E, et al. Placental anionic and cationic amino acid transporter expression in growth hormone overexpressing and null IGF-II or null IGF-I receptor mice. Placenta 1999;20:639-50. 